\title{
Commentary \\ Mammographic breast density as a biomarker of effects of isoflavones on the female breast
}

\author{
Charlotte Atkinson* and Sheila A Bingham ${ }^{+}$ \\ *Fred Hutchinson Cancer Research Center, Seattle, Washington, USA \\ ${ }^{\dagger}$ MRC Dunn Human Nutrition Unit, Wellcome Trust/MRC Building, Cambridge, UK
}

Correspondence: Sheila A. Bingham, MRC Dunn Human Nutrition Unit, Wellcome Trust/MRC Building, Hills Road, Cambridge CB2 2XY, UK. Tel: +44 1223 252760; fax: +44 1223 252765; e-mail: sab@mrc-dunn.cam.ac.uk

Received: 9 July 2001

Revisions requested: 24 July 2001

Revisions received: 12 September 2001

Accepted: 18 September 2001

Published: 25 October 2001
Breast Cancer Res 2002, 4:1-4

(C) 2002 BioMed Central Ltd

(Print ISSN 1465-5411; Online ISSN 1465-542X)

\begin{abstract}
Isoflavones possess both estrogenic and anti-estrogenic actions, and are hypothesized to protect against breast cancer. However, two intervention studies of markers of proliferation on breast tissue have raised concerns that soy isoflavones may have an estrogenic effect on breast tissue. Increased mammographic breast density is associated with an elevated risk of breast cancer, although the mechanism underlying this relationship has not been explained. Estrogens increase and anti-estrogens decrease breast density. Breast density may therefore serve as a biomarker of estrogenic or antiestrogenic effects of a treatment on breast tissue. The effect of isoflavones on breast density is under investigation.
\end{abstract}

Keywords: breast cancer, diet, hormones, isoflavones, mammographic density

\section{Isoflavones}

Isoflavones are polyphenolic compounds naturally present in foods of plant origin that bear a striking structural similarity to the mammalian estrogens. Soybeans, and products made from soybeans, are by far the richest identified sources of isoflavones (Table 1), and it has been hypothesized that soy consumption in Asian populations may contribute to the lower incidence of breast cancer and other hormone-dependent conditions in Eastern versus Western populations [1]. Isoflavones are capable of binding to estrogen receptors $\alpha$ and $\beta$ [2], and they are weak estrogens. In common with other weak estrogens, and similar to selective estrogen receptor modulators such as tamoxifen, isoflavones can act as both estrogen agonists and estrogen antagonists, the latter suggesting potential antiproliferative effects of isoflavones on breast tissue. In Western diets, the lignans, another class of phytoestrogens, are quantitatively more important than isoflavones, but the evidence for lignans possessing estrogenic and/or anti-estrogenic activities is less well established, and fewer data are available on their potential beneficial health effects in humans.

\section{Epidemiology}

There are few prospective studies on the effects of isoflavones on breast cancer risk. In a recent large-scale, population-based case-control study among Chinese women, intake of soy foods during adolescence, a period when breast tissue is particularly sensitive to environmental stimuli, was associated with a significant reduction in breast cancer risk in later life [3]. In one of the largest studies to date, however, neither tofu nor miso consumption had a significant effect on risk of breast cancer among almost 35,000 women living in Hiroshima and Nagasaki, Japan [4]. No strong confirmation of an effect of soy on reducing risk of breast cancer is thus apparent from exist- 
Table 1

\begin{tabular}{lc} 
Isoflavone content of some common foods \\
\hline \multicolumn{1}{l}{$\mu \mathrm{g} / \mathrm{kg}$ wet weight (Da $+\mathrm{Gen})$} \\
\hline Peas, fresh, cooked & nd \\
Asparagus, cooked & nd \\
Carrots, old, cooked & $\mathrm{nd}$ \\
Cucumber, with skin & 2.9 \\
Potatoes, old, cooked & 7.4 \\
Potatoes, new, cooked & 37.5 \\
Red kidney beans, cooked & 222.7 \\
Chickpeas, dried, cooked & 241.4 \\
French beans, cooked & 350.3 \\
Beansprouts, mung, raw & 5736 \\
Soy cheese & 34,000 \\
Soymilk & 44,000 \\
Tofu yogurt & 151,000 \\
Soy hot dog, tempeh burger & 188,000 \\
Tofu & 242,000 \\
Soybeans, dried, cooked & 469,000 \\
Miso & $1,265,000$ \\
\hline
\end{tabular}

Data from Liggins et al. [24], and Reinli and Block [25]. Da, Daidzein; Gen, Genistein; nd, not detected.

ing studies, but no studies to date have identified an increased risk of breast cancer associated with elevated intakes of isoflavones.

\section{Clinical intervention trials}

There are many trials in the literature designed to investigate the mechanisms whereby isoflavones may protect against breast cancer. However, two have raised concerns that isoflavones may exert estrogenic effects on breast tissue. Petrakis et al. [5] reported an increase in the presence of epithelial hyperplasia in nipple aspirate fluid from premenopausal and postmenopausal women following a 6-month soy protein intervention, and Hargreaves et al. [6] reported changes in estrogen-regulated proteins in nipple aspirate fluid that were indicative of an estrogenic response among premenopausal women following a 14day soy protein intervention. Interestingly, Hargreaves et al. also reported significantly higher concentrations of both daidzein and genistein in nipple aspirate fluid than in paired serum samples, suggesting that isoflavones may accumulate within the breast ducts [6]. Thus, although isoflavones are thought to be protective over breast cancer, it is not clear what effect they may have on breast tissue, and a bioassay of their effects is needed.

\section{Breast density}

The mammographic appearance of the breast differs between individuals according to the relative proportions of radiologically dense connective and epithelial tissues, and of radiologically lucent fat. Increased radiological density has consistently been associated with an increased risk of breast cancer since the 1970s. Investigators have used both qualitative (e.g. Wolfe's classification system) and quantitative assessments of breast density (reviewed in [7]). Quantitative assessments, including computer-assisted techniques, have generally been associated with larger gradients in risk of breast cancer than qualitative assessments [7] and, to date, the majority of studies have expressed breast density as a percentage of the breast occupied by dense tissue. The absolute area of dense tissue is also associated with risk of breast cancer (see [7] and references cited therein). In a study among women from a multi-ethnic population, women with small total breast areas had higher percent densities but lower absolute densities than women with large total breast areas [8]. It is not yet clear, however, whether one method of expressing breast density is preferable over the other.

In a review of case-control studies using quantitative methods of determining density, odds ratios for women in the highest versus lowest extents of density (expressed as percent density) ranged from 2.1 to 6.0 [7]. These odds ratios are of a greater magnitude than relative risks incurred from established breast cancer risk factors such as early age at menarche and late age at menopause [9].

Potentially, therefore, breast density is an intermediate risk marker for breast cancer. The mechanism underlying increased breast density is not fully understood, but a number of factors have been associated with breast density changes.

\section{Hormones}

There is much evidence that breast density is sensitive to changes in a woman's hormonal milieu. Breast density increases when a woman begins hormone replacement therapy and decreases when she discontinues (see [10] and references cited therein). Furthermore, fewer women have dense breasts after the menopause compared with before the menopause (reviewed in [7]). It has recently been shown that the anti-estrogen tamoxifen decreases breast density [11-13]. A hormonal contraceptive regimen designed to reduce exposure of the breast to estrogen and progesterone also reduced mammographic density [14]. The contrasting effects of estrogens and anti-estrogens on breast density, and the increased risk of breast cancer associated with dense breasts, suggest that it may be useful as a biomarker of estrogenic or antiestrogenic effects of a treatment on breast tissue. High circulating levels of insulin-like growth factor (IGF)-I and low circulating levels of IGF binding protein (IGFBP)-3 
have also been associated with increased mammographic density in premenopausal women [15]. Since IGFs increase cell proliferation and IGFBPs inhibit proliferation, it has been suggested that increased breast density might result from stimulation of cell proliferation by IGF-I and/or impaired inhibition of proliferation resulting from low levels of IGFBP-3 [15].

\section{Genetic factors}

A family history of breast cancer has been positively associated with breast density in some, although not all, studies. In a cohort study of families with a history of breast cancer, segregation analysis suggested that a major autosomal gene influences breast density (see [7] and references cited therein). It has been suggested that $B R C A 1$ carriers might have increased breast density due to mammary epithelial hyperplasia brought about by a defect in the tumor suppressor gene, but to date this has not been shown [16]. One study has examined polymorphisms in low penetrance genes controlling steroid hormone metabolism in relation to percent breast density in women selected on the basis of having Wolfe's P2 or DY breast patterns. Sample sizes within genotypes were small, however, and there were no clear associations between polymorphisms in CYP17 ( $T \rightarrow C$ substitution at the $5^{\prime}$ promoter), CYP19 ( $G \rightarrow T$ substitution on intron 6$)$ or estrogen receptor ( $C \rightarrow T$ substitution on intron 1) genes and percentage breast density [17].

\section{Diet}

Data from both observational and intervention studies on diet and mammographic densities have suggested that intakes of certain nutrients can influence breast density. A 2-year low-fat, high-carbohydrate intervention resulted in a significantly greater decrease in absolute area of breast density than occurred in controls consuming a self-selected diet, particularly among women who became postmenopausal during the study [18]. Further analysis of this subgroup showed that reduction in total or saturated fat intake or cholesterol intake was significantly associated with the decrease in dense area, and the most significant dietary variable associated with the reduction in percentage density was reduction in cholesterol intake [19]. In a large cohort study of breast cancer families, however, increased breast density was associated with decreased intakes of saturated fat in premenopausal women [20]. Positive associations between alcohol intakes and breast density have generally been found, although in the breast cancer family cohort white wine was positively associated and red wine negatively associated with density [20]. Positive associations between breast density and total protein and carbohydrate intakes [21] and with intakes of vitamins $B_{12}, C$, and $E$ [20] have also been described. It remains to be determined, however, by what mechanism the diet influences breast density, but it has been suggested that effects may occur via diet-induced alterations in sex hormone levels [18].

\section{Isoflavones and breast density}

If breast density is a marker of breast cancer risk, and isoflavones protect against breast cancer, more lucent breasts might be expected to occur in Asian women. Two cross-sectional studies have examined this. In the first, premenopausal Japanese women had a significantly lower proportion of dense breast patterns and a higher proportion of lucent breast patterns than did British women. The authors did not measure diet, but suggested their findings might be attributable to environmental factors such as diet, since they were unable to find correlations between measurements of endocrine function and breast density [22]. A second cross-sectional study of a multi-ethnic population living in Hawaii, in which soy intakes and mammographic densities were investigated, was not able to confirm this suggestion. Chinese and Japanese women had higher percent densities than Caucasian and Native Hawaiian women (but had lower absolute densities), and there was a significant trend towards higher percent breast density with increasing quartiles of soy-food intake. This relationship was not apparent using absolute area of dense tissue [8]. In a randomized, placebo-controlled trial of an isoflavone supplement $(40 \mathrm{mg}$ clover-derived isoflavones per day for 1 year) in women selected on the basis of having Wolfe's P2 or DY breast patterns, a decrease in density was observed in the intervention and placebo groups, but the difference between treatments was not statistically significant $(P>0.05)$. When divided into tertiles according to age, women aged $56-65$ years in the isoflavone group experienced a significantly greater decrease in density than women aged 56-65 years in the placebo group $(P<0.05)$. Sample sizes within tertiles of age were small, however, and a larger study is needed to confirm these findings [23]. In a subset of women who had been genotyped for polymorphisms in CYP17 ( $T \rightarrow C$ substitution at the $5^{\prime}$ promoter), CYP19 ( $G \rightarrow T$ substitution on intron 6$)$, and estrogen receptor $(C \rightarrow T$ substitution on intron 1) genes, there was no effect of genotype on change in breast density [17].

\section{Conclusions and future work}

Despite the rapid increase in the extent of research into isoflavones in recent years, there remains a lack of data on which to base recommendations regarding intakes either for patients with breast cancer or healthy women wishing to reduce their risk of breast cancer. Mammographic breast density has the potential to act as a biomarker of estrogenic or anti-estrogenic effects of isoflavones on breast tissue. Further studies are needed to determine the effects of higher doses of isoflavones, effects of long-term isoflavone consumption, and effects of isoflavones consumed at various stages of life on breast tissue. Placebocontrolled intervention trials are the optimal method for determining the effects of a standardized dose of isoflavones. Such trials are potentially problematic, however, in terms of ethical issues associated with the 
necessity to carry out repeat mammography. Observational prospective or cross-sectional study designs could provide information on the effects of dietary isoflavones without the need for additional mammography, and would enable large populations to be studied in relatively short periods of time.

\section{References}

1. Adlercreutz $\mathrm{H}$ : Western diet and Western diseases: some hormonal and biochemical mechanisms and associations. Scand $J$ Clin Lab Invest 1990, 201(suppl):3-21.

2. Kuiper GG, Carlsson B, Grandien K, Enmark E, Haggblad J, Nilsson S, Gustafsson JA: Comparison of the ligand binding specificity and transcript tissue distribution of estrogen receptors alpha and beta. Endocrinology 1997, 138:863-870.

3. Shu XO, Jin F, Dai Q, Wen W, Potter JD, Kushi LH, Ruan Z, Gao YT, Zheng W: Soyfood Intake during Adolescence and Subsequent Risk of Breast Cancer among Chinese Women. Cancer Epidemiol Biomarkers Prev 2001, 10:483-488.

4. Key TJ, Sharp GB, Appleby PN, Beral V, Goodman MT, Soda M, Mabuchi K: Soya foods and breast cancer risk: a prospective study in Hiroshima and Nagasaki, Japan. Br J Cancer 1999, 81:1248-1256.

5. Petrakis NL, Barnes S, King EB, Lowenstein J, Wiencke J, Lee MM, Miike R, Kirk M, Coward L: Stimulatory influence of soy protein isolate on breast secretion in pre- and postmenopausal women. Cancer Epidemiol Biomarkers Prev 1996, 5:785-794.

6. Hargreaves DF, Potten CS, Harding C, Shaw LE, Morton MS, Roberts SA, Howell A, Bundred NJ: Two-week dietary soy supplementation has an estrogenic effect on normal premenopausal breast. J Clin Endocrinol Metab 1999, 84:40174024.

7. Boyd NF, Lockwood GA, Byng JW, Tritchler DL, Yaffe MJ: Mammographic densities and breast cancer risk. Cancer Epidemiol Biomarkers Prev 1998, 7:1133-1144.

8. Maskarinec G, Meng L: An investigation of soy intake and mammographic characteristics in Hawaii. Breast Cancer Res 2001, 3:134-141.

9. Kelsey JL, Bernstein L: Epidemiology and prevention of breast cancer. Annu Rev Public Health 1996, 17:47-67.

10. Rutter CM, Mandelson MT, Laya MB, Seger DJ, Taplin S: Changes in breast density associated with initiation, discontinuation, and continuing use of hormone replacement therapy. JAMA 2001, 285:171-176.

11. Atkinson C, Warren R, Bingham SA, Day NE: Mammographic patterns as a predictive biomarker of breast cancer risk: effect of tamoxifen. Cancer Epidemiol Biomarkers Prev 1999, 8:863-866.

12. Brisson J, Brisson B, Cote G, Maunsell E, Berube S, Robert J: Tamoxifen and mammographic breast densities. Cancer Epidemiol Biomarkers Prev 2000, 9:911-915.

13. Chow CK, Venzon D, Jones EC, Premkumar A, O'Shaughnessy J, Zujewski J: Effect of tamoxifen on mammographic density. Cancer Epidemiol Biomarkers Prev 2000, 9:917-921.

14. Spicer DV, Ursin G, Parisky YR, Pearce JG, Shoupe D, Pike A, Pike MC: Changes in mammographic densities induced by a hormonal contraceptive designed to reduce breast cancer risk. J Natl Cancer Inst 1994, 86:431-436.

15. Byrne C, Colditz GA, Willett WC, Speizer FE, Pollak M, Hankinson SE: Plasma insulin-like growth factor (IGF) I, IGF-binding protein 3, and mammographic density. Cancer Res 2000, 60: 3744-3748.

16. Helvie MA, Roubidoux MA, Weber BL, Merajver SD: Mammography of breast carcinoma in women who have mutations of the breast cancer gene BRCA1: initial experience. $A m$ J Roentgenol 1997, 168:1599-1602.

17. Atkinson C: The effects of isoflavones on some risk factors for breast cancer, osteoporosis, and ischaemic heart disease [Doctoral Thesis]. Cambridge: Cambridge University; 2000.

18. Boyd NF, Greenberg C, Lockwood G, Little L, Martin L, Byng J, Yaffe M, Tritchler D: Effects at two years of a low-fat, highcarbohydrate diet on radiologic features of the breast: results from a randomized trial. Canadian Diet and Breast Cancer Prevention Study Group. J Natl Cancer Inst 1997, 89:488-496.
19. Knight JA, Martin LJ, Greenberg CV, Lockwood GA, Byng JW Yaffe MJ, Tritchler DL, Boyd NF: Macronutrient intake and change in mammographic density at menopause: results from a randomized trial. Cancer Epidemiol Biomarkers Prev 1999, 8:123-128.

20. Vachon CM, Kushi LH, Cerhan JR, Kuni CC, Sellers TA: Association of diet and mammographic breast density in the Minnesota breast cancer family cohort. Cancer Epidemiol Biomarkers Prev 2000, 9:151-160.

21. Sala E, Warren R, Duffy S, Welch A, Luben R, Day N: High risk mammographic parenchymal patterns and diet: a casecontrol study. Br J Cancer 2000, 83:121-126.

22. Gravelle IH, Bulbrook RD, Wang DY, Allen D, Hayward JL, Bulstrode JC, Takatani O: A comparison of mammographic parenchymal patterns in premenopausal Japanese and British women. Breast Cancer Res Treat 1991, 18(suppl 1):S93-S95.

23. Atkinson C, Warren RMLW, Dowsett M, Day NE, Bingham SA: Effects of isoflavones on breast density oestradiol, and gonadotrophins: a double blind randomised placebo controlled trial [abstract P2-652]. Endocrine Society Annual Meeting Program Abstracts. Bethesda: Endocrine Society Press; 2001:433.

24. Liggins J, Bluck LJ, Runswick S, Atkinson C, Coward WA, Bingham SA: Daidzein and genistein contents of vegetables. Br J Nutr 2000, 84:717-725.

25. Reinli K, Block G: Phytoestrogen content of foods - a compendium of literature values. Nutr Cancer 1996, 26:123-148. 